\title{
Modern Challenges in The Application of Personalized Models in Student Education for The Benefit of Business and Society
}

\author{
$\mathrm{PhD}$ candidate Petya Petrova \\ University of Economics - Varna, Varna, Bulgaria \\ petya.p.petrova@ue-varna.bg
}

\begin{abstract}
With each passing day, consumers, particularly students, expect more intelligent and personalized services. The key to providing such services is the concept of a personalized model. Applying appropriate personalized learning models to students is a process that is filled with many challenges. The main purpose of the current report is to explore the challenges that impede the design and implementation of models that are strictly customized to the interests of students. In order to achieve this goal, it is necessary to explore the contemporary factors that are essential in designing personalization models. The factors are mainly related to the requirements of the business towards professionalism among students, as well as the goals set by the state for the education improvement. In order to achieve this goal, it is also necessary to investigate the technologies by which the personalization of models is realized and by which successful implementation of the personalized models is ensured in the students' education.
\end{abstract}

Keywords: Personalized Model, Appropriate Personalized Learning, Learning Students, Education Goals, Learning Scales.

JEL Code: A29

DOI: https://doi.org/10.36997/IJUSV-ESS/2020.9.3.88

\section{Introduction}

With each passing day, consumers, in particular students, expect more intelligent and personalized services. The key point needed to provide such services is the concept of a personalized model. The application of appropriate personalized models for student learning is a process associated with many challenges. The main purpose of the current report is to examine the challenges that hinder the identification and application of models that are strictly personalized to the interests of students. To achieve this goal, it is necessary to study modern factors that are essential in the design of personalization models. The factors are mainly related to the requirements of the business in relation to quality staff among students, as well as to the goals set by the government for the development of education. In order to achieve the goal, it is necessary to study at the same time the technologies through which the personalization of the models is realized and through which the successful implementation of the personalized models in the students' education is ensured.

\section{Modern challenges in the application of personalized models.}

The world we live in today is characterized by close cooperation between business and education. The reason is that companies are increasingly looking for specialists in educational institutions, believing that this is where they will find quality staff. In this regard, it is necessary for educational institutions to look for new ways to educate their students, preparing them as the best specialists in their field. In order to meet the requirements of business, it is necessary to identify and implement personalized learning models that cover most of the interests of students, strengthen their participation in learning, as a result of which students can acquire more theoretical knowledge, but also practical skills important for business. The application of such models is associated with various challenges, which arise from various aspects. In management circles, the four characteristics of the acronym VUCA $^{1}$ (Dimitrova, 2020), which are defined as the four main elements to ensure business competitiveness today, play a key role in good governance. The characteristics are related to the main challenges before the application of personalized models in

\footnotetext{
${ }^{1}$ VUCA - Volatility, Uncertainty, Complexity, Ambiguity.
} 
the education of students, considered in the following sequence:

- Volatility - describes the dynamics of the changes that take place around us on a daily basis and to which we must adapt. Nowadays the world is changing with extraordinary dynamics, respectively the technologies, as well as the views and interests of the people are constantly changing. Dynamic development is a challenge to the application of personalized models, because it requires a broad study of students' interests before the model itself is developed and applied. This is a difficult task in such a dynamic environment, which requires the joint efforts of specialists in the field of education, business, and even in the field of psychology. As a result, it will be possible to offer appropriate models that are closely personalized according to the interests of students and the needs of business;

- Uncertainty - describes the inability to predict how things will develop in this changing environment. Therefore, one of the challenges to the application of personalized models is to anticipate to some extent the difficulties, shortcomings, problems that will arise when using personalized training. Overcoming it is related to the need to consider models that reveal the risks of applying personalized models, which must be relatively flexible in order to be able to be updated daily, covering the new personal requirements of students;

- Complexity - describes the interconnectedness of the factors that affect our work and the problems we face. Identifying the critical factors on which the successful implementation of personalized learning models depends is one of the main challenges. The complexity lies in the challenge of determining which of the factors are a priority for students to engage in the personalized model. The complexity also relates to the fact that appropriate technologies should be chosen to propose appropriate models. It is necessary to make SWOT analyzes in order to reveal the strengths and weaknesses of the impact of various factors, as a result of which correct personalized models in education are distinguished;

- Ambiguity - describes the novelty of the emerging situations. Increasingly, we are facing unprecedented cases in which we cannot build on previous experience and need innovative solutions. The lack of clarity is one of the most important challenges in applying personalized models. When designing the models, there is a risk of identifying as important such priorities for students that are not really of interest to them. This is a critical factor for the failure of the application of the model, which requires consideration of different circumstances, different points of view, different aspects affecting the interests of students in education. Once all important aspects have been clarified, appropriate personalization models can be identified in student learning.

As a result of the considered VUCA characteristics, we can summarize that the development of business is directly related to the development of the proposed methods in education, which must correspond to the knowledge economy. The need for a "knowledge economy" is the priority of innovative ideas over conventional factors of production (labor and capital) (Luksha, 2017). We can say that education is already perceived as a strategic condition for the development of digitalization in general. In 2015, the United Nations General Assembly adopted the resolution "Transforming our world: a Sustainable Development Agenda 2030", which serves as a guide for the entire world community for the coming years (Ferri, 2015). Among the 17 global goals set out in the resolution are "ensuring inclusive and equitable quality education and promoting lifelong learning opportunities". At the same time, modern education is seen as a value in itself and as a tool for solving and preventing economic, social and environmental problems. This position identifies two main approaches to goal setting (Akopov, 2005). The first - technological - is aimed at implementing the "social order" and providing material and technical support for the life of society, focused on the socialization of young generations, training students with a set of key competencies, professionals with a certain level of knowledge and skills. The advantage lies in the effectiveness of solving urgent problems, ensuring the sustainability of the social system, which is achieved through regulation. The second approach - humanistic - in which humanistic goals are aimed at the 
development of the individual, its creative powers, self-expression in activity. For the purposes of the research, the technological approach and the challenges related to it are of interest.

\section{Technological challenges in the application of personalized models.}

It should be noted that great hopes have recently been placed on educational technologies, but they also pose serious challenges. At the beginning of the 21 st century, there is an optimistic belief that education is about to lead to a technological revolution. In the beginning of 2010, multiuser online courses (MOOC - Massive Open Online Courses) appeared, which are an important step towards the application of a personalized model in education. However, the revolution has not yet taken place, with only a few minor changes in traditional educational processes and programs. Many radical tools are offered, but it is not clear how students will use them, because many people simply cannot determine their educational goals and the means to achieve them. As a result, most class-based "innovations" support an outdated assessment and certification system and are based on traditional methods of communication between teachers and students. Among the main reasons are the lack of integrated platforms that could assemble different educational modules and solutions in a personal trajectory; lack of necessary regulatory and management decisions; lack of trust on the part of employers, parents and society; a low proportion of "self-governing" students with flexible "learn to learn" group skills, as well as a lack of understanding of the importance of future changes in the education system itself. In this regard, some authors (Luksha, Cubista and Laslo, 2018) believe that the technological development of education should be seen as an important but not the only condition for modernization.

The identified challenges would be overcome by creating a digital platform for personalized education. Technical solutions must take into account the social context of their application in conditions of limited opportunities (Fischer and Sugimoto, 2006). In this regard, it is necessary to identify the main priorities for building a personalized model. Providing clear guidance is one of the necessary conditions for personalization. Clarity of goals and understanding of the level of their achievements are one of the most important factors for the effectiveness of training (Hattie, 2009, 2015, 2017). The subjective position of the student in relation to the goals of education is one of the main principles of the personalized model of education (PME). The focus is on the student, who takes the initiative in connection with learning, chooses learning goals and ways to achieve them, plans his/her work and is responsible for the result, working in the field of his/her most progressive development. In this case, the leading motivation is the joy of knowledge, not duty, fear or reward. The content of the training is formed to the level of a separate educational task and is structured according to "big ideas" and not according to separate topics, concepts, facts. The digital platform acts as a space for building and implementing a personalized learning path, not as educational aid or an e-textbook. It contains the necessary resources (scales, teaching materials, assignments, tools for diagnosis and assessment, etc.) to achieve educational goals at each level, taking into account the individual requirements of the student and the organization of joint activities, as well as analytical and management tools for monitoring and evaluating the quality of education for its subjects (students, teachers, administrators) (Kazakova, 2019).

The orientation towards the goals and not towards the topics, the choice of educational goals and the level of their achievement by the student himself/herself is a system-forming factor in the personalized model of education. The educational goal is those actions that the student can perform, a class of tasks that he can solve (Yermakov and Kirillov, 2019). The description of the goal is formulated by the student - in understandable language ("What will I learn?", "Why do I need this?", "How will this be evaluated?"); in active form - a way to achieve an educational result, and not only indicating the subject of activity (facts, concepts, knowledge, etc.) on the basis of accepted taxonomies, taking into account the $\mathrm{SMART}^{2}$ criteria. Based on this, a special technology is used in

${ }^{2}$ SMART - Specific, Measurable, Attainable, Relevant, Time-bound. 
determining the goals in the personalized learning model - technology of scalable learning goals. It is expressed in the provision of clear guidelines - what educational goals should be achieved in general, what are the minimum necessary results that the government requires, what is the educational organization as a necessary condition for personalization. To build an individual trajectory based on these guidelines, the goals must be equal, as it is necessary to demonstrate to the student: 1) what needs to be achieved? (target level); 2) what simpler skills and knowledge need to be mastered? (basic level); 3) what can be done with the acquired knowledge, skills, how to develop them further? (advanced level). This results in a scalable learning objective. The scale is a structured level of expected goal setting (Zukerman, 1999). The scaling approaches may be different, as shown in Table 1.

Table 1 Approaches for scaling learning objectives

\begin{tabular}{|c|c|c|c|}
\hline Grounds for scaling & Example & Advantages & Disadvantages \\
\hline $\begin{array}{c}\text { Volume of study } \\
\text { material }\end{array}$ & $\begin{array}{l}\text { At the first level the } \\
\text { learner knows } 10 \text { terms, } \\
\text { at the second - } 15\end{array}$ & $\begin{array}{l}\text { Easy compilation, } \\
\text { level determination }\end{array}$ & $\begin{array}{l}\text { Orientation largely to } \\
\text { memory, not to } \\
\text { complete knowledge }\end{array}$ \\
\hline $\begin{array}{c}\text { Volume of work on } \\
\text { mastering the study } \\
\text { material, } \\
\text { presentation of the } \\
\text { learning outcomes }\end{array}$ & $\begin{array}{l}\text { At the first level - "read } \\
\text { in the textbook", at the } \\
\text { second "prepare a } \\
\text { reference summary", at } \\
\text { the third "make a } \\
\text { project" }\end{array}$ & $\begin{array}{l}\text { Understandable for } \\
\text { students, gives the } \\
\text { impression of justice }\end{array}$ & $\begin{array}{l}\text { The large volume of } \\
\text { work done does not } \\
\text { mean higher quality } \\
\text { and mastery of the } \\
\text { teaching material }\end{array}$ \\
\hline $\begin{array}{c}\text { Share of completed } \\
\text { tasks }\end{array}$ & $\begin{array}{l}\text { At the first level - } \\
\text { minimum volume of } \\
\text { completed tasks from } \\
\text { the planned ones (eg } \\
10 \% \text { ), at the last level - } \\
100 \%\end{array}$ & $\begin{array}{l}\text { Easy compilation, } \\
\text { determining the level } \\
\text { understandable for } \\
\text { students }\end{array}$ & $\begin{array}{l}\text { The quality and } \\
\text { complexity of the } \\
\text { tasks are not taken } \\
\text { into account, } \\
\text { depending on the } \\
\text { specific list of tasks }\end{array}$ \\
\hline $\begin{array}{l}\text { Cognitive } \\
\text { complexity }\end{array}$ & $\begin{array}{l}\text { At the first level - } \\
\text { simple cognitive actions } \\
\text { and tasks, at the last - } \\
\text { the most complex }\end{array}$ & Developing character & $\begin{array}{l}\text { Complexity in } \\
\text { development }\end{array}$ \\
\hline
\end{tabular}

In the personalized learning model, goals are scaled according to the levels of cognitive complexity of educational tasks based on the technique developed by R. Marzano (Marzano, 2006). Later, R. Marzano and J. Kendall (Marzano and Kendall, 2007) presented an audit of the taxonomy of B. Bloom's learning objectives (Anderson et al., 2001) (Table 2).

Table 2 Comparison of taxonomy

\begin{tabular}{|c|l|}
$\begin{array}{c}\text { Following the model of } \\
\text { Anderson and Bloom }\end{array}$ & \multicolumn{1}{c|}{ Following the model of Marzano and Kendall } \\
\hline Create & $\begin{array}{l}\text { Knowledge utilization: decision-making, problem- } \\
\text { solving, experimenting, investigating }\end{array}$ \\
\hline Evaluate & Analysis \\
\hline Analyze & Comprehension \\
\hline Apply & Retrieval \\
\hline Understand &
\end{tabular}

While taxonomic data provide some linearity to the learning process, they serve as a useful guide in formulating learning objectives and tasks, as well as in selecting tasks. Both models can be 
used to build scales within a customized learning model. Below (Table 3) is a variant of R. Marzano's approach, adapted for a personalized learning model.

Table 3 Scaling of learning objectives in PME

\begin{tabular}{|c|c|c|}
\hline Level & Level characteristic & Learning tasks (sample descriptors) \\
\hline 0.0 & $\begin{array}{l}\text { Zero - in the presence of } \\
\text { help, the student does not } \\
\text { achieve results }\end{array}$ & It is not considered in the PME \\
\hline 1.0 & $\begin{array}{l}\text { Presence of readiness for } \\
\text { training - in the presence } \\
\text { of help, the student } \\
\text { partially achieves the } \\
\text { results of levels } 2.0 \text { and } 3.0\end{array}$ & It is not considered in the PME \\
\hline 2.0 & $\begin{array}{l}\text { Basic - non-mechanical } \\
\text { reproduction (the learner } \\
\text { not only learns the terms, } \\
\text { but can explain their } \\
\text { meaning and give an } \\
\text { example), perform actions } \\
\text { on a template (direct } \\
\text { application of formulas } \\
\text { and algorithms), individual } \\
\text { elements and complex } \\
\text { action. }\end{array}$ & $\begin{array}{l}\text { Learning: identification, determination (in a list, in a } \\
\text { figure), selection (from a list), making a judgment (true / } \\
\text { false). } \\
\text { Memorization: name, list, description, condition, fact. } \\
\text { Execution: use, demonstration, display, making, planning, } \\
\text { completion. }\end{array}$ \\
\hline 3.0 & $\begin{array}{l}\text { Target - analysis, synthesis } \\
\text { of a few simple elements, } \\
\text { understanding, establishing } \\
\text { relationships, patterns in } \\
\text { relation to various } \\
\text { examples and } \\
\text { circumstances }\end{array}$ & $\begin{array}{l}\text { Integration: summarizing, paraphrasing, describing (key } \\
\text { points, the relationship between; the ways in which ..; how } \\
\text { and why, impacts). } \\
\text { Symbolization: use of the model, presentation / } \\
\text { representation in the form of ... (graph, diagram, etc.); } \\
\text { illustration, display. } \\
\text { Match: Derive the characteristics, find similarities and } \\
\text { differences, arrange them into categories, suggest an } \\
\text { analogy or metaphor. } \\
\text { Classification: organization, ranking, classification } \\
\text { (including by various criteria), grouping in a general } \\
\text { category. } \\
\text { Error analysis: editing, identifying, correcting errors, } \\
\text { evaluating, identifying inaccuracies / misunderstandings, } \\
\text { giving a critical conclusion, diagnosing. } \\
\text { Summary: drawing conclusions; formulation of principles / } \\
\text { rules; development tracking; making a summary; making } \\
\text { deductions. } \\
\text { Clarification: proposal and argumentation ...; forecasting } \\
\text { and making predictions (what will happen when ..); } \\
\text { determining the conditions under which ... }\end{array}$ \\
\hline 4.0 & $\begin{array}{l}\text { Advanced - research, } \\
\text { design, transfer of } \\
\text { knowledge and skills in } \\
\text { another field, synthetic } \\
\text { (covers different topics }\end{array}$ & $\begin{array}{l}\text { Decision making: choosing the best option, finding the } \\
\text { optimal course of action, making a decision. } \\
\text { Problem solving: determination; adaptability; strategy } \\
\text { development; finding an opportunity to overcome ..; } \\
\text { finding a solution in specific conditions. }\end{array}$ \\
\hline
\end{tabular}


from one subject /

discipline),

interdisciplinary skill, application of knowledge

in real situations
Experimentation: testing an idea; proposing and testing hypotheses; finding an experimental explanation; establishing whether it is possible; construction of plots on the basis of experimental data.

Research: learning about; determining his/her position in relation to; finding the causes and mechanism of the phenomenon; forecasting of a process / phenomenon depending on the condition.

The interrelationships between the goals of the different levels and years of study provide an area of the most progressive development of the student. For example, the target level for the second year of study can be considered advanced level for the first year of study, which allows the student to present his/her own path of promotion, to assess his/her current level. Additional choice is provided by formulating the goal of level 4.0 in a generalized form with an example: "Applying the acquired knowledge in a new context, for example ..." (in this case the student himself can offer his own version).

We can note that the scale is neither a curriculum or a calendar-thematic plan, nor a collection. There is no need to include everything that is in the content of the topic. If some individual concepts, abilities, skills were not included in the scale at the planning stage, it does not mean that they cannot be studied. The scale also does not prescribe a bottom-up or top-down procedure ("simple to complex", "specific to general" or vice versa). The course of the learning process is determined by the teacher together with the student, taking into account the characteristics of a particular subject / discipline, study material.

To implement the considered technology of scalable learning objectives, we will explore some technical tools that successfully support the models of personalized learning of students. These are the following more interesting tools:

* Seesaw (Remote Learning With Minecraft, 2020) - A student-centered digital portfolio that documents student learning with built-in creative tools and provides an authentic audience for student work;

* Soundtrap (Soundtrap for Education Offers Extended Trials to Support Schools, 2020) - A cloud-based recording studio that uses intelligent thinking and communication skills through collaborative, creative audio recording projects and links to lessons needed to prepare 21 st century students for the global technology world;

* Wevideo (Online Video Editor, 2020) - Cloud-based platform for video editing and digitization of training courses;

* ExplainEverything (Kucirkova, Audain and Chamberlain, 2018) - A cloud collaboration platform built on tomorrow's technology that helps students and faculty tell their unique story.

* Minecraft (Minecraft Education, 2016) - Provides unique and creative training for teachers and students by providing an open-world game that encourages creativity, collaboration and problem solving in a shared environment where the only constraint is your imagination.

These tools are only part of the possibilities through which the models of personalized learning of students can be realized. Personalized learning, backed by digital tools, builds a solid foundation for student success in college and beyond. This statement is evidenced by the results of a study made by the Gates Foundation (Rand Corporation, 2014), which shows that using personalized math training significantly improves test results. Based on this statement, the tendency to invest in technologies for advanced education based on personalized models is increasing. According to a study by edTech (Southwick, 2020), investments in personalization of learning are made in technologies in several main areas: 
- Virtual Reality (VR) and Augmented Reality (AR) in Education - Interplay Learning provides \$ 5.5 million in 2019 for 3D VR training. The creator of Pokemon Go! - Niantic Labs invested \$ 245 million in 2019 in AR training applications

- Use of Artificial Intelligence (AI) and Machine Learning in Education: Adaptive Learning. AI-based tools such as Knewton, Quizlet, Kidaptive, KidSense and Querium implement machine learning systems to improve education. For teachers who evaluate the use of these tools in the classroom, questions about algorithmic bias, privacy risks, and efficiency are essential.

- Robotics in Education - products like Roybi use robots and artificial intelligence to help with early learning and language acquisition. Another company that seeks to solve the cost and hardware problems of maintaining a fleet of learning robots at school is Robotify, which teaches coding and robotics in a virtual environment.

- Blockchain in Education - companies with blockchain-based solutions for the educational space use the technology to provide and verify degrees and credentials.

The chart below from HolonIQ shows the exponential growth of investment in these areas in education expected over the next five years.

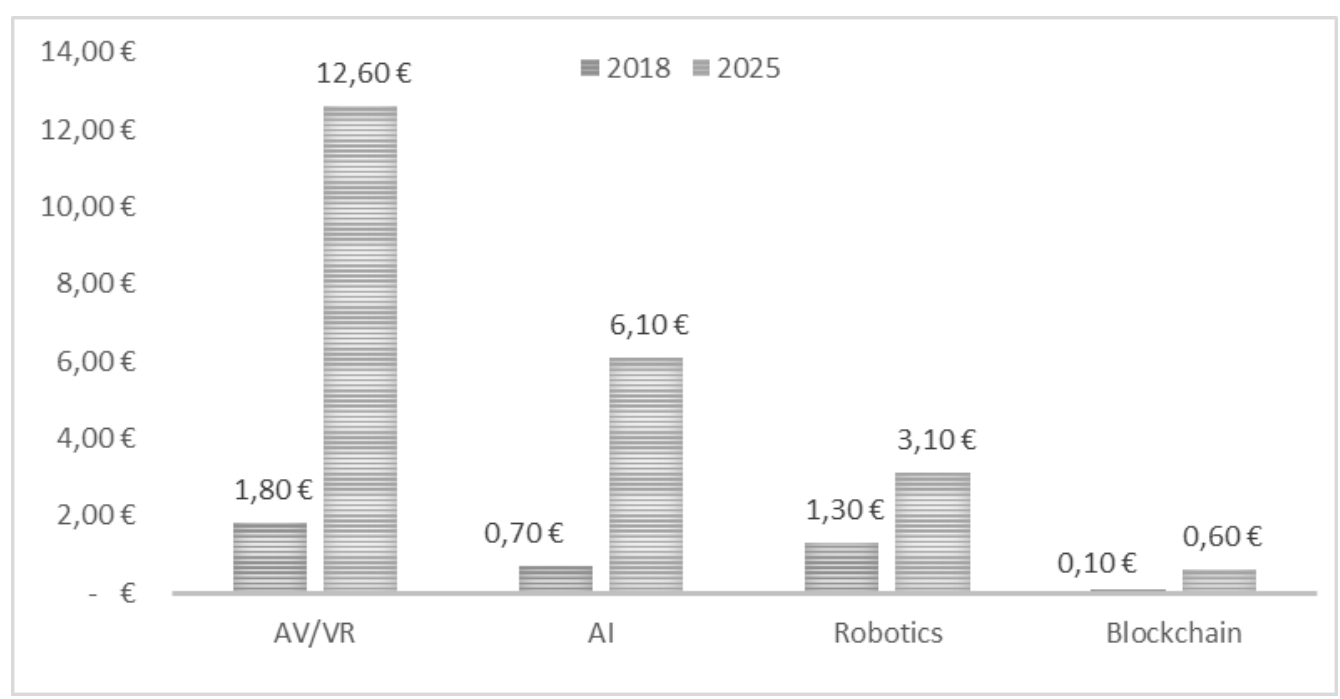

Figure 1 Expenditures for technologies for personalization in education 2018 against 2025 (\$87bn+ of Global EdTech funding predicted through 2030, 2020)

\section{Conclusion}

The results of the study show that nowadays the application of personalized models in training is an important factor for businesses that need professionals in their work. At the same time, development in education is among the priorities of the government, which adopts special programs for sustainable development. The successful application of personalized models in student education will contribute to a significant evolution in the field of education, but it is associated with many challenges. The study showed that these challenges are related to key business elements such as variability, uncertainty, complexity and ambiguity that make up the acronym VUCA. At the same time, the problem of educational goals is relevant in psychological, pedagogical and sociocultural terms. We found that two main strategies for setting goals interact - technological (mass) and humanitarian (personal). For a number of reasons, technology itself cannot be seen as the only tool to modernize education. It is necessary to combine technical solutions with psychological and pedagogical innovations, in connection with which we have explored some basic technological tools that can be used in the formation of models for personalization in student learning. The study also shows that investment in e-learning is increasing, there is even a clear trend to increase it by 2025, which is a clear indication that personalized models are becoming a leading criterion for the 
development of modern education.

\section{References}

1. $\$ 87 b n+$ of Global EdTech funding predicted through 2030 (2020). Available at: https://www.holoniq.com/notes/87bn-of-global-edtech-funding-predicted-to-2030/.

2. Akopov, G. V (2005) 'Tseli obrazovaniya i razvitie soznaniya uchaushtihsya', Sibirskii prihologicheskij jurnal, 22, pp. 105-110.

3. Anderson, L. W. et al. (2001) A taxonomy for learning, teaching, and assessing: A revision of Bloom's taxonomy of educational objectives. Available at: https://www.uky.edu/ rsand1/china2018/texts/Anderson-Krathwohl - A taxonomy for learning teaching and assessing.pdf.

4. Dimitrova, A. (2020) Za liderstvoto vyv VUCA sveta. Available at: https://www.openspacecollective.com/our-blog/vuca (Accessed: 29 April 2020).

5. Ferri, N. (2015) 'United nations general assembly. Transforming our world: the 2030 Agenda for sustainable development', International Journal of Marine and Coastal Law, 25(2), pp. 271-287. doi: 10.1163/157180910X12665776638740.

6. Fischer, G. and Sugimoto, M. (2006) 'Supporting self - directed learners and learning communities with sociotechnical environments', Research and practice in technology enhanced learning, 1(1), pp. 31-64.

7. Hattie, J. (2009) 'Visible Learning: a synthesis of over 800 meta-analyses relating to achievement', London; New York: Routledge, Taylor \& Francis Group, 9, p. 378.

8. Hattie, J. (2015) 'The applicability of Visible Learning to higher education', Scholarship of teaching and learning in psychology, 1(1), p. 79-91.

9. Hattie, J. (2017) 'Vidimoe obuchenie', Natsionalnoe obrazovanie, p. 495.

10. Kazakova, Y. I. (2019) 'Personalizirovannaya model' obrazovaniya Vyzovy vremeni', Platforma novoy shkoly, p. 36.

11. Kucirkova, N., Audain, J. and Chamberlain, L. (2018) Explain Everything, Jumpstart! Apps. doi: $10.4324 / 9781315674452-8$.

12. Luksha, P. (2017) Obrazovaniye 20.35. Chelovek Tom 7 Seriya 03 Chem Delat'?

13. Luksha, P., Cubista, D. and Laslo, A. (2018) Education for complex society. Global Education Futures. Moscow, Russia.

14. Marzano, R. J. (2006) 'Classroom assessment and grading that work', Association for supervision and curriculum development.

15. Marzano, R. J. and Kendall, J. S. (2007) 'Praise for the Second Edition of The New Taxonomy of Educational Objectives', Corwin Press, pp. i-ii. doi: 10.1016/B978-1-85617-816-7.10013-X.

16. Minecraft Education (2016). Available at: education.minecraft.net (Accessed: 29 April 2020).

17. Online Video Editor (2020). Available at: https://www.wevideo.com/ (Accessed: 29 April 2020).

18. Rand Corporation (2014) 'Early Progress', (November). Available at: http://k12education.gatesfoundation.org/wp-content/uploads/2015/06/Early-Progress-onPersonalized-Learning-Full-Report.pdf.

19. Remote Learning With Minecraft (2020). Available at: https://web.seesaw.me/ (Accessed: 29 April 2020).

20. Soundtrap for Education Offers Extended Trials to Support Schools (2020). Available at: https://www.soundtrap.com/edu/ (Accessed: 29 April 2020).

21. Southwick, S. (2020) EdTech Industry Analysis \& Trends. Available at: https://www.toptal.com/finance/market-research-analysts/edtech-trends-2020 (Accessed: 29 April 2020).

22. Yermakov, D. S. and Kirillov, P. N. (2019) 'Personalizirovannaya model' v tsifre', Obrazovatel'naya politika, 3(79), pp. 132-141.

23. Zukerman, G. A. (1999) 'Otsenka bez otmetki', Riga: Ped. tsentr 'Experiment', p. 146. 